\title{
Clinical Findings of Patients Undergone Surgery for Testicular Torsion: A 12-Year Single Center Experience in Northern Iran
}

\author{
Hamid Shafi'1,2, Amin Zarghami3 ${ }^{3}$ Arsalan Aliramaji1 ${ }^{*}$, Maryam Rahimi2 \\ ${ }^{1}$ Department of Urology, Babol University of Medical Science, Babol, Iran \\ ${ }^{2}$ Clinical Research Developing Center, Babol University of Medical Science, Babol, Iran \\ ${ }^{3}$ Student Research Committee, Babol University of Medical Sciences, Babol, Iran \\ Email: dr hamidshafi@yahoo.com, aminzarghami18@yahoo.com, ${ }^{*}$ drramagi@yahoo.com, \\ m.rahimi1223@yahoo.com
}

Received 4 March 2014; revised 4 April 2014; accepted 11 April 2014

Copyright (C) 2014 by authors and Scientific Research Publishing Inc.

This work is licensed under the Creative Commons Attribution International License (CC BY). http://creativecommons.org/licenses/by/4.0/

(c) $\underset{\mathrm{EY}}{\mathrm{E}}$ Open Access

\begin{abstract}
Introduction: Testicular torsion is a surgical emergency which requires early diagnosis and prompt surgical management to avoid testicular damage. The aim of this study is to survey the clinical findings and outcome of the patients treated for testicular torsion in a university hospital in Babol, northern Iran. Methods: In this cross sectional study, a retrospective survey of all cases presenting with acute scrotum and primarily diagnosed as testicular torsion was conducted during 2001 and 2012 in Babol, northern Iran. All 103 cases were reviewed and several clinical data, including duration of symptoms and operative findings were collected. Findings: 0 f 103 patients who presented to the emergency department with acute scrotum, the median age of the cases was 16.0 years. Thirty four percent of the patients presented emergency unit less than 6 hours from symptom exposure. Pain $\mathbf{( 9 5 . 1 \% )}$ was the major symptom in all patients. Surgery revealed that $72(70.9 \%)$ cases were diagnosed firmly as testicular torsion that 23 patients underwent orchidectomy for a necrotic torsed testis. There were significant differences between orchiectomized versus non-orchiectomized torsion cases in affected side, symptom presentation to operation time. Conclusion: According to our results more than half of the cases presented more than in the golden time. Late presentation to hospital was the major cause of delay leading to orchidectomy in patients with testicular torsion. Greater effort in health education and direct or selfreferal to hospital may reduce this delay.
\end{abstract}

\section{Keywords}

Testicular Torsion, Orchidectomy, Orchiopexy

\footnotetext{
"Corresponding author.
}

How to cite this paper: Shafi, H., et al. (2014) Clinical Findings of Patients Undergone Surgery for Testicular Torsion: A 12-Year Single Center Experience in Northern Iran. Open Journal of Urology, 4, 63-69. 


\section{Introduction}

Testicular torsion is a common acute surgical emergency with the annual incidence of 1 in 4000 males younger than 25 years [1]. It has two peaks in age distribution occurring in the perinatal and early adolescent age groups [2]. As a matter of fact, any male in the peripubertal age presenting with acute scrotal pain should be presumed to have testicular torsion and diagnostic evaluation should be utilized until otherwise confirmed [3].

Evaluation of acute scrotal pathology should begin with a thorough history, followed by a detailed examination of the abdomen, testes, epididymis, cord, scrotal skin, and inguinal region. In equivocal acute scrotal cases, color Doppler ultrasonography is the diagnostic choice. Age, sudden onset and worsening scrotal pain, nausea/ vomiting, absence of ipsilateral cremasteric reflex, horizontal or high riding testicular position and scrotal skin changes have been shown to be predictive of torsion. Misdiagnosing testicular torsion can lead to organ loss, cosmetic deformity, and compromised fertility [4] [5]. The differential diagnosis of the acutely painful scrotum includes: testicular torsion, trauma, epididymitis/orchitis, incarcerated hernia, varicocele, idiopathic scrotal edema, and torsion of the appendix testis [6].

According to pathological aspect, testicular torsion is an acute vascular event results in rotation of the testicular vascular pedicle resulting in testicular ischaemia and ultimately infarction. Irreversible parenchymal damage will develop if a testicle is twisted. It could cause immediate circulatory changes and long-term sequelae such as testicular function and fertility [7] [8]. A rapid diagnosis of torsion of the cord, if present, is essential, and emergency surgical exploration must be performed whenever testicular torsion is clinically suspected. If left untreated, irreversible ischaemia starts appearing in 6 hours. Beyond the six hours, the chances of saving the testis reduce over the next 48 hours [9]. The ideal treatment is surgical exploration and orchidectomy with contralateral orchidopexy or bilateral orchidopexy depending on the condition of the affected testis. If surgical options are delayed then manual detorsion should be attempted [10].

According to the authors' knowledge, there was no previous report from north of Iran. Thus, the aim of this study is to survey the clinical findings and outcome of the patients treated for testicular torsion in Shahid-Beheshti university hospital in Babol, northern Iran.

\section{Patients \& Methods}

Retrospective single-centre review of male primarily treated as testicular torsion was performed. We included all the patients who were presenting with acute scrotal pain to the Shahid Beheshti university hospital of Babol, northern Iran, between 2001 and 2012 with the primary diagnosis of testicular torsion. Surgical and emergency department records consisted of age, clinical symptoms, time from symptom occurred to hospital presentation, time from admission to operating surgery, Doppler ultra-sonography, surgical and pathological findings were recorded. The authors identified visits with testicular torsion using International Classification of Disease. In all the cases surgery was performed. The data extracted from the files and those with major incomplete contents, exclude from the study. Statistical data analysis was performed by SPSS18 (Chicago-IL). ManneWhitney test was used to compare continuous variables and chi-square and Fisher's exact test to compare categorical variables. A p-value less than 0.05 was considered statistically significant.

\section{Results}

In total 103 patients were evaluated based on the hospital records during the 12 years period of study. All these patients had undergone surgery. The mean age of patients was $17.71 \pm 6.36$, with the median age of 16 years (range 6 to 45 years old). Autumn \& winter were slightly more prevalent presentation season (53/103). Sixty one (59.2\%) patients were affected on the left side and 42 (40.8\%) on the right. Pain (95.1\%) was the major symptom among our cases, and swelling (35.9\%), nausea/vomiting (15.5\%) and erythema (10.7\%) were declared respectively. Forty one (39.8\%) patients were operated on within one hour of their presentation to the emergency ward and 61 (59.2\%) cases more than this time. Thirty five (34\%) of the patients presented in to emergency unit less than 6 hours from symptom exposure and 59 (57.3\%) individuals more than 6 hours and the information of 9 cases were missing. Doppler ultrasonography was utilized for 37 (35.9\%) patient due to diagosis. Surgery revealed that 72 (69.9\%) cases diagnosed firmly as testicular torsion (Table 1), which 26 (36.1\%) patients underwent orchiectomy (23/26 cases was performed contralateral orchiopexy) for a necrotic torsed testis which in their pathological reports, mostly, hemorrhagic infarction had been stated. On the other hand, 29 patients were performed detortion (28/29 cases was performed contralateral orchiopexy) and others remained underwent or- 
chiopexy, exclusively. Among those who were orchiectomized, 23 orchiopexy was performed 23 cases. Therefore, in only 72 of 103 cases (69.9\%) primary preoperative diagnosis confirmed surgically. In the follow up, there was no readmission record found. Nineteen patients underwent removal of the testicular appendix. Post operative follow-up of our patients indicated no atrophy progress in those patients with confirmed viable and lasting testes during surgery.

According to Mann-Whitney test, there was no significant difference between the age of patients diagnosed as testicular torsion and others $(\mathrm{p}=0.177)$. After classification of age in to two groups (Adults and adolescents (less than 18yrs)), there was no significant difference between diagnosis of torsion and other differential diagnosis. Also, there was no significant difference between season and occurance of torsion. There were significant differences between orchiectomized versus non-orchiectomized testicular torsion cases in affected side, symptom presentation time to operating surgery (door to OR time) which were indicated in Table 2.

\section{Discussion}

Emergent evaluation of patients presented with acute scrotal pain should begin with a thorough history taking, detailed physical examination of the abdomen, testes, epididymis, cord, scrotal skin, and inguinal region, and noting paraclinical findings such as: complete blood count, urinalysis. Extra attention should be paid to the onset, quality and duration of the pain, swelling and other symptoms that may matter. On the other hand, history of previous perineal trauma, presence of urinary tract infection and sexual exposure or habits should be mentioned. In equivocal acute scrotal cases, color Doppler ultrasonography as an initial imaging modality is the diagnostic choice, because of well specifcity and greater availability. Although radionuclide testicular scintigraphy can be a diagnostic tool when past the acute phase in helping to make or exclude the diagnosis. Once the diagnosis of testicular torsion is confirmed, the rapid restoration of the blood flow to the testis is critical. This can be accomplished by manual detorsion through a surgery or in the case of necrosis orciectomy [11]-[14].

According to our findings most of the cases were affected in the left side and bilateral involvement was rare but in an african study with the similar range of age to our study only $36 \%$ presented with testicular torsion with the more frequency in the right side (41.3\%). In 23.3\% cases both testicles were involved [15].

Pain (95.1\%) was the most prevalent symptom in our study population and almost all the patients declared this as a chief complaint. Besides, swelling, nausea and erythema were on the next ranks respectively. Liang, T. et al. reported that sudden-onset scrotal pain (88\%), abnormal position (86\%), and absent cremasteric reflex

Table 1. The frequency of post operative final diagnosis of the patients in our study.

\begin{tabular}{cc}
\hline Diagnosis & Frequency \\
\hline Testicular Torsion & $72(69.9 \%)$ \\
Testicular Appendix & $19(18.4 \%)$ \\
Others (e.g. epidydimitis, etc.) & $12(11.7 \%)$ \\
Total & $103(100 \%)$ \\
\hline
\end{tabular}

Table 2. Management overview of 72 patients presenting with testicular torsion over a 12-year period.

\begin{tabular}{|c|c|c|c|c|c|}
\hline Variables & & $\begin{array}{l}\text { Orchiectomized } \\
\text { group } n=26\end{array}$ & $\begin{array}{l}\text { Non-orchiectomized } \\
\text { group } n=46\end{array}$ & p value & $95 \%$ CI \\
\hline \multirow{3}{*}{ Age group } & Adolescents & $15(57.7 \%)$ & 31 (67.4\%) & \multirow{3}{*}{0.41} & \multirow{3}{*}{-} \\
\hline & & & & & \\
\hline & Adults & 11 (42.3\%) & $15(32.6 \%)$ & & \\
\hline \multirow{3}{*}{ Side } & Left & $15(57.7 \%)$ & 12 (23.9\%) & \multirow{3}{*}{0.004} & \multirow{3}{*}{$1.54-12.17$} \\
\hline & & & & & \\
\hline & Right & $11(42.3 \%)$ & 35 (76.1\%) & & \\
\hline \multirow{2}{*}{ Door to OR time* } & Less than 6 hours & $0(0 \%)$ & $12(26.1 \%)$ & \multirow{2}{*}{0.006} & \multirow{2}{*}{$1.39-2.16$} \\
\hline & More than 6 hours & 25 (100\%) & 34 (73.9\%) & & \\
\hline
\end{tabular}

${ }^{*}$ The data of 1 case was missing. 
(91\%) were more prevalent in torsion patients [1]. In a single-centre review of 94 boys, presentation included pain (76\%), scrotal swelling (65\%) and abdominal symptoms (22\%) [16]. Yu et al. revealed that pain duration and left side manifestation are independent risk factors of testicular torsion [8]. Altogether, concentration to the pain symptom and its pattern of presentation is a crucial point in diagnosis of acute scrotal pathology.

Several authors agree that adolescent patients presenting with testicular swelling while those above this age range appeared as orchitis [10] [17]. The range of age in our study population covers both adolescents and adults. Our results indicated that there was no significant difference between age groups versus diagnosis. Besides, this non-significant different was consistent in the outcome of surgery between young and adults which was similar to the findings of Grushevesky et al. [18]. In a 9-year retrospective study by Cummings et al., they demonstrated that males aged 21 to 34 years had more orchiectomies than those aged 8 to 20 years and time to presentation was the key factor for testicular salvage. Despite of the higher frequency of orchiectomy among adults, there was no statistically significant difference between the adults and adolescents groups in the time presentation and outcome of surgery [19].

Previous studies of the seasonality of testicular torsion have yielded conflicting results [20]. Although the autumn and winter were prevalent seasons for tosion occurance; but the difference versus first six months of year was not significant in our study; so as the same report of Cost et al. [21]. In contrast, Grushevsky et al. in USA, determined that testicular torsion occurrence were more likely in the winter compared with the summer [18]. This finding was similar to the two decades study of Korkes et al. in Brazil [22]. It was also demonstrated that temperature and humidity correlated the risk of testicular torsion according to findings of Srinivasan et al. [5].

The main causes of testicular necrosis after torsion are late presentation of the patient to the hospital, incorrect initial diagnosis and delay in treatment at referral hospital. Our findings indicated the high rate of $66.7 \%$ which presented more than the 6 hrs golden time. This is a questionable and worring rate. We found significant difference between the duration of symptom presentation and hospital refer and surgery operation (door to OR time) in those who testis preserving approach was performed and those who underwent orchiectomy (Table 2). It was previously mentioned in literatures that duration of symptoms for more than golden time and a higher age of patients are described to be risk factors for testicular loss [23]. Ringdahl and Teague indicated that the salvage rates in patients with testicular torsion were $90 \%, 50 \%$ and less than $10 \%$ in those seeking medical attention within 6, 12 and 24 hours after the onset of pain, respectively [24]. In a follow up study in pediatric center in Denmark, loss of testicular tissue was significantly associated with long preoperative duration of symptoms and with low postoperative sperm counts [25]. These results was consistent with another follow up study in Greece [26]. Liang $\mathrm{T}$ revealed that the mean times from presentation at the emergency department to ultrasound and surgery were 209.4 and 309.4 minutes, respectively. Of the torsed testicles, $69 \%$ were salvageable [1]. Sessions et al. revealed that, up to $40 \%$ of testes cannot be salvaged [27]. It is well-known that testicular ischaemia undoubtedly leads to testicular atrophy. Taskinen et al. could not find an association between the duration of symptoms and the degree of testicular atrophy. The most probable explanation that could be offered is the fact that on the clinical aspect, the symptom occurrence may not essentially caused by fully occlusion of perfusion [23]. In an imaging study $26 \%$ of the patients were detected to have some intratesticular circulation despite clinical testicular torsion [28].

According to our findings, 26 patients underwent orchiectomy and 29 patients were performed detortion and others remained underwent orchiopexy, exclusively. Among those who were orchiectomized, 23 orchiopexy was performed 23 cases. Saxena reported that orchiectomy was performed during initial exploration in 41, with significantly higher rates of orchiectomies in patients with late $(>6 \mathrm{~h})$ versus patients with early referrals $(<6 \mathrm{~h})$ [16]. Also, In another study, testicular torsion was confirmed in 39 of the suspected 47 cases after surgical exploration. Twnety-one of these 39 testicular torsion patients underwent orchiectomy, and 18 were rescued and underwent orchiopexy [8]. Results from subsaharan africa and Taiwan revealed the rate of $15.7 \%$ and $25.6 \%$ for ending up with removal of the testis. In contrast to our removal rate of $36.1 \%$ seemed to be similar. According to these findings, despite of testis preserving approach in most of the cases, the rate of loss is still high and questionable [15] [29]. In our study no relapse had been reported according to follow up. Although the literature is synonymous with testicular salvage and orchidopexy and/or orchiectomy and contralateral orchidopexy for testicular torsion, recurrent torsion may occur years following the primary procedure which can be viewed as technical failure [30] [31].

Modem ultrasound examination of the scrotum is an indispensable imaging modality for the clinical assessment of patients with acute scrotal pathology and yields high accuracy compared with surgical exploration. A 
key component of the testicular examination is use of power and spectral Doppler ultrasonography [32]. We should mention that the greatest limitation of our study was the incapablity of utilizing Doppler ultrasonography for all of the patients during the approach to diagnosis. This was mainly because of that in half of the study period since 2000 this method had not been routinely performed in our center. On the other hand the availability to the radiologist in emergency unit was not possible most of the time and the urologist had to make a clinical decision based on his own clinical experience.

In contrast with other studies, almost more than half of our study population lately presented for more than the golden time and this is a questionable matter of discussion in health system. In fact, male subjects may be hesitant to seek medical attention for conditions involving their genitals, even for torsion. On the other hand, this issue matters more than many countries among religious country such as Iran. This may because the shame of presenting the sexual organs and issues that exist in our culture. One study found that the majority of male respondents did not respond appropriately to symptoms of serious testicular pathology and 36\% did not think that it was necessary to seek attention for testicular swelling and pain [33]. We essentially need to pay the individuals' attention to their symptoms and those that really need urgent procedures. This could not be accomplished except by extra attention of health centers to the KAP programs and developing the general populations knowledge in such issues.

\section{Conclusion}

In conclusion as determined in our study, the majority of patients presenting late ( $>6$ h) require orchiectomy owing to testicular necrosis. Chances of testicular salvage after torsion are higher if patients present early. The message to patients should be that scrotal pain, especially severe pain, requires immediate evaluation. Moreover, the message to the national organizations may be that the male health guidelines should be revised and earlier education about testicular health should be included.

\section{Acknowledgements}

We would like to thank all the personnel of the Shahid Beheshti research developing center for their cooperation in this project. We also appreciate Mr. Mostafa Mostafazadeh Bora and Mr. Milad Motevali for their assistant in data collection and the executive process. Funding and support conducted by vice chancellor of research and technology of Babol University of medical sciences.

\section{References}

[1] Liang, T., Metcalfe, P., Sevcik, W. and Noga, M. (2013) Retrospective Review of Diagnosis and Treatment in Children Presenting to the Pediatric Department with Acute Scrotum. American Journal of Roentgenology, 200, W444-449. http://dx.doi.org/10.2214/AJR.12.10036

[2] Lopez, R.N. and Beasley, S.W. (2012) Testicular Torsion: Potential Pitfalls in Its Diagnosis and Management. Journal of Paediatrics and Child Health, 48, E30-32. http://dx.doi.org/10.1111/j.1440-1754.2011.02205.x

[3] Mansbach, J.M., Forbes, P. and Peters, C. (2005) Testicular Torsion and Risk Factors for Orchiectomy. Archives of Pediatrics and Adolescent Medicine, 159, 1167-1171. http://dx.doi.org/10.1001/archpedi.159.12.1167

[4] Blaivas, M. and Brannam, L. (2004) Testicular Ultrasound. Emergency Medicine Clinics of North America, 22, 723748. http://dx.doi.org/10.1016/j.emc.2004.04.002

[5] Srinivasan, A., Cinman, N., Feber, K.M., Gitlin, J. and Palmer, L.S. (2011) History and Physical Examination Findings Predictive of Testicular Torsion: An Attempt to Promote Clinical Diagnosis by House Staff. Journal of Pediatric Urology, 7, 470-474. http://dx.doi.org/10.1016/j.jpurol.2010.12.010

[6] Edelsberg, J.S. and Surh, Y.S. (1988) The Acute Scrotum. Emergency Medicine Clinics of North America, 6, 521-546.

[7] Pentyala, S., Lee, J., Yalamanchili, P., Vitkun, S. and Khan, S.A. (2001) Testicular Torsion: A Review. Journal of Lower Genital Tract Disease, 5, 38-47.

[8] Yu, K.J., Wang, T.M., Chen, H.W. and Wang, H.H. (2012) The Dilemma in the Diagnosis of Acute Scrotum: Clinical Clues for Differentiating between Testicular Torsion and Epididymo-Orchitis. Chang Gung Medical Journal, 35, 3845.

[9] Visser, A.J. and Heyns, C.F. (2003) Testicular Function after Torsion of the Spermatic Cord. BJU International, 92, 200-203. http://dx.doi.org/10.1046/j.1464-410X.2003.04307.x 
[10] Kapoor, S. (2008) Testicular Torsion: A Race against Time. International Journal of Clinical Practice, 62, 821-827. http://dx.doi.org/10.1111/j.1742-1241.2008.01727.x

[11] Karmazyn, B., Steinberg, R., Kornreich, L., Freud, E., Grozovski, S., Schwarz, M., et al. (2005) Clinical and Sonographic Criteria of Acute Scrotum in Children: A Retrospective Study of 172 Boys. Pediatric Radiology, 35, 302-310. http://dx.doi.org/10.1007/s00247-004-1347-9

[12] Slijper, N., Sukhotnik, I., Toubi, A. and Mogilner, J. (2007) Critical Validation of Ultrasound Doppler in the Diagnosis of Torsion of Undescended Testis. Israel Medical Association Journal, 9, 99-101.

[13] Prando, D. (2009) Torsion of the Spermatic Cord: The Main Gray-Scale and Doppler Sonographic Signs. Abdominal Imaging, 34, 648-661. http://dx.doi.org/10.1007/s00261-008-9449-8

[14] Lavallee, M.E. and Cash, J. (2005) Testicular Torsion: Evaluation and Management. Current Sports Medicine Reports, 4, 102-104. http://dx.doi.org/10.1097/01.CSMR.0000306081.13064.a2

[15] Baruga, E. and Guyton Munabi, I. (2013) Case Series on Testicular Torsion: An Educational Emergency for Sub-Saharan Africa. The Pan African Medical Journal, 14, 18.

[16] Saxena, A.K., Castellani, C., Ruttenstock, E.M. and Höllwarth, M.E. (2012) Testicular Torsion: A 15-Year SingleCentre Clinical and Histological Analysis. Acta Paediatrica, 101, e282-e286. http://dx.doi.org/10.1111/j.1651-2227.2012.02644.x

[17] Shergill, I.S., Gupta, S., Arya, M. and Patel, H.R. (2003) Testicular Torsion: A Twist to the Tale. International Journal of Clinical Practice, 57, 353.

[18] Grushevsky, A., Allegra, J.R., Eskin, B. and McCarthy, C. (2011) The Seasonality of Testicular Torsion. Pediatric Emergency Care, 27, 1146-1147. http://dx.doi.org/10.1097/PEC.0b013e31823aba2e

[19] Cummings, J.M., Boullier, J.A., Sekhon, D. and Bose, K. (2002) Adult Testicular Torsion. The Journal of Urology, 167, 2109-2110. http://dx.doi.org/10.1016/S0022-5347(05)65096-3

[20] Molokwu, C.N., Somani, B.K. and Goodman, C.M. (2011) Outcomes of Scrotal Exploration for Acute Scrotal Pain Suspicious of Testicular Torsion: A Consecutive Case Series of 173 Patients. BJU International, 107, 990-993. http://dx.doi.org/10.1111/j.1464-410X.2010.09557.x

[21] Cost, N.G., Bush, N.C., Barber, T.D., Huang, R. and Baker, L.A. (2011) Pediatric Testicular Torsion: Demographics of National Orchiopexy versus Orchiectomy Rates. The Journal of Urology, 185, 2459-2463. http://dx.doi.org/10.1016/j.juro.2011.01.016

[22] Korkes, F., Cabral, P.R., Alves, C.D., Savioli, M.L. and Pompeo, A.C. (2012) Testicular Torsion and Weather Conditions: Analysis of 21,289 Cases in Brazil. International braz j urol, 38, 222-228. http://dx.doi.org/10.1590/S1677-55382012000200010

[23] Taskinen, S., Taskinen, M. and Rintala, R. (2008) Testicular Torsion: Orchiectomy or Orchiopexy? Journal of Pediatric Urology, 4, 210-213. http://dx.doi.org/10.1016/j.jpurol.2007.11.007

[24] Ringdahl, E. and Teague, L. (2006) Testicular Torsion. American Academy of Family Physicians, 74, 1739-1743.

[25] Brasso, K., Andersen, L., Kay, L., Wille-Jørgensen, P., Linnet, L. and Egensem, J. (1993) Testicular Torsion: A Follow-Up Study. Scandinavian Journal of Urology and Nephrology, 27, 1-6. http://dx.doi.org/10.3109/00365599309180406

[26] Tryfonas, G., Violaki, A., Tsikopoulos, G., Avtzoglou, P., Zioutis, J., Limas, C., et al. (1994) Late Postoperative Results in Males Treated for Testicular Torsion during Childhood. Journal of Pediatric Surgery, 29, 553-556. http://dx.doi.org/10.1016/0022-3468(94)90090-6

[27] Sessions, A.E., Rabinowitz, R., Hulbert, W.C., Goldstein, M.M. and Mevorach, R.A. (2003) Testicular Torsion: Direction, Degree, Duration and Disinformation. The Journal of Urology, 169, 663-665. http://dx.doi.org/10.1016/S0022-5347(05)63987-0

[28] Kalfa, N., Veyrac, C., Lopez, M., Lopez, C., Maurel, A., Kaselas, C., et al. (2007) Multicenter Assessment of Ultrasound of the Spermatic Cord in Children with Acute Scrotum. The Journal of Urology, 177, 297-301. http://dx.doi.org/10.1016/j.juro.2006.08.128

[29] Huang, W.Y., Chen, Y.F., Chang, H.C., Yang, T.K., Hsieh, J.T. and Huang, K.H. (2013) The Incidence Rate and Characteristics in Patients with Testicular Torsion: A Nationwide, Population-Based Study. Acta Paediatrica, 102, e363e367. http://dx.doi.org/10.1111/apa.12275

[30] Mor, Y., Pinthus, J.H., Nadu, A., Raviv, G., Golomb, J., Winkler, H., et al. (2006) Testicular Fixation Following Torsion of the Spermatic Cord-Does It Guarantee Prevention of Recurrent Torsion Events? The Journal of Urology, 175, 171-173. http://dx.doi.org/10.1016/S0022-5347(05)00060-1

[31] Bolln, C., Driver, C.P. and Youngson, G.G. (2006) Operative Management of Testicular Torsion: Current Practice within the UK and Ireland. Journal of Pediatric Urology, 2, 190-193. http://dx.doi.org/10.1016/j.jpurol.2005.07.006 
[32] Yang Jr., C., Song, B., Liu, X., Wei, G.H., Lin, T. and He, D.W. (2011) Acute Scrotum in Children: An 18-Year Retrospective Study. Pediatric Emergency Care, 27, 270-274. http://dx.doi.org/10.1097/PEC.0b013e318213144e

[33] Nasrallah, P., Nair, G., Congeni, J., Bennett, C.L. and McMahon, D. (2000) Testicular Health Awareness in Pubertal Males. The Journal of Urology, 164, 1115-1117. http://dx.doi.org/10.1016/S0022-5347(05)67265-5 